OPEN ACCESS

Edited by: Albert Costa,

Universitat Pompeu Fabra, Spain

Reviewed by:

Patrick Bonin,

University of Bourgogne and Institut Universitaire de France, France

Kalinka Timmer,

Leiden University, Netherlands

*Correspondence: Qingfang Zhang,

Department of Psychology, Renmin

University of China,

59 Zhongguancun Street, Haidian

District, Beijing 100872, China qingfang.zhang@ruc.edu.cn

Specialty section: This article was submitted to Language Sciences, a section of the journal Frontiers in Psychology

Received: 11 December 2014 Accepted: 30 March 2015 Published: 17 April 2015

Citation:

Zhang Q and Wang C (2015) Phonology is not accessed earlier than orthography in Chinese written production: evidence for the orthography autonomy hypothesis. Front. Psychol. 6:448. doi: 10.3389/fpsyg.2015.00448

\section{Phonology is not accessed earlier than orthography in Chinese written production: evidence for the orthography autonomy hypothesis}

\author{
Qingfang Zhang ${ }^{1,2 *}$ and Cheng Wang ${ }^{2}$
}

${ }^{1}$ Department of Psychology, Renmin University of China, Beijing, China, ${ }^{2}$ Key Laboratory of Behavioral Science, Institute of Psychology - Chinese Academy of Sciences, Beijing, China

The contribution of orthographic and phonological codes to written production remains controversial. We report results using a picture-word interference task in which participants were asked to write (Experiments 1 and 2) or to speak (Experiment 3) the names of pictures while trying to ignore visual distractors, and the interval between the target and distractor onset was varied. Distractors were orthographically plus phonologically related, orthographically related, phonologically related, or unrelated to picture names. For written production, we found an exclusive orthographic effect at an early stage, reflecting a fast and direct link between meaning and graphemic lexicon, and we demonstrated that orthographic codes can be accessed directly from meaning in healthy adults. We also found orthographic and phonological effects at a later stage, reflecting a slow and indirect link between meaning and graphemic lexicon via phonology. Furthermore, the absence of an interaction effect of orthographic and phonological facilitation on written latencies suggests that the two effects are additive in general and that they might occur independently in written production in Chinese. For spoken production, we found that orthographic and phonological effects occur simultaneously in spoken production and that the two effects are additive at an early stage but interactive at a later stage. The temporal courses and their interplay of orthographic and phonological effects are dissociative in written and spoken production. Our findings thus support the orthography autonomy hypothesis, rather than the obligatory phonological mediation hypothesis, in written production in Chinese (as a non-alphabetic script).

Keywords: written production, spoken production, orthography, phonology, orthographic autonomy hypothesis

\section{Introduction}

Over the past few decades, much research has investigated the processes and mechanisms underlying spoken production (Dell, 1986, 1988; Levelt et al., 1999). However, less work has been devoted to understanding written production. The current views of speech production provide a general theoretical framework from which hypotheses specific to writing can be derived (Bonin et al., 1997, 1998a,b, 2013; Rapp et al., 1997; Bonin and Fayol, 2000; Baus et al., 2013; Damian and Qu, 2013; Zhang and Wang, 2014). In the work reported here, we investigated how orthographic codes are 
accessed from the conceptual/semantic level in writing using a picture-word interference (PWI) paradigm, which is an experimental paradigm that is popular in speech production (i.e., Schriefers et al., 1990; Starreveld and La Heij, 1995, 1996a,b; Damian and Martin, 1999).

A central debate in the field is the contributions of orthographic and phonological codes (e.g., Qu et al., 2011; Bonin et al., 2013; Damian and Qu, 2013). Early theoretical accounts claimed that the retrieval of an orthographic representation was entirely dependent on the prior retrieval of phonological codes, which is called the OBLIGATORY phonological mediation hypothesis (Geschwind, 1969; Luria, 1970). This account is compatible with the common introspective speaking experience in writing (Hotopf, 1980) and the observation of phonologically mediated spelling errors such as homophone substitutions (e.g., there for their) or quasi-homophone substitutions (e.g., dirth for dearth; Aitchison and Todd, 1982). Evidence in brain-damaged patients and normal writers indicates that spelling errors occur more frequently with inconsistent rather than consistent spelling (i.e., Bonin et al., 2001), reflecting that phonology influences orthographic output. Neuropsychological patients with writing disorders present comparable impairments in spoken and written production (Luria, 1970; Basso et al., 1978), as the phonological mediation hypothesis predicts.

However, neuropsychological studies have demonstrated dissociations between spoken and written production. Studies have repeatedly reported that the ability to spell is often spared even when phonological production is severely damaged (e.g., Caramazza et al., 1983; Hanley and McDonnell, 1997). Miceli et al. (1997) reported a patient who, when presented with a picture, sometimes generated different spoken and written responses (e.g., in response to a picture of a cook, the patient would say dish but write forks; see Alario et al., 2003 for a similar case study). Rapp et al. (1997) presented the case of a neurologically impaired individual who was often able to write the names of pictures correctly but was unable to provide the correct spoken names of the pictures (e.g., in response to a picture of tweezers, the patient would say pliers but write needle; see also Caramazza, 1997 for details). These findings motivated the "orthographic autonomy hypothesis," which assumes that individuals can gain access to orthographic representation directly from meaning without phonological mediation (Rapp and Caramazza, 1997).

This account, however, does not necessarily imply that intact writing is unaffected by phonological codes in unimpaired individuals. Based on Miceli et al.'s (1997) proposal, Bonin et al. (2001) proposed a working model of written picture naming (see Figure 1). When a target picture is presented, the first processing step involves object identification and conceptual preparation in that order. These representations send activation to phonological and orthographic lexicons in parallel, and there are bidirectional connections between two lexicons. The orthographic autonomy hypothesis assumes that semantic activation can directly flow to the orthographic lexicon (by link A in Figure 1). Miceli et al. (1997) distinguished weak and strong versions of the orthographic autonomy hypothesis. The weak version stipulates that both the orthographic and phonological lexicons are directly

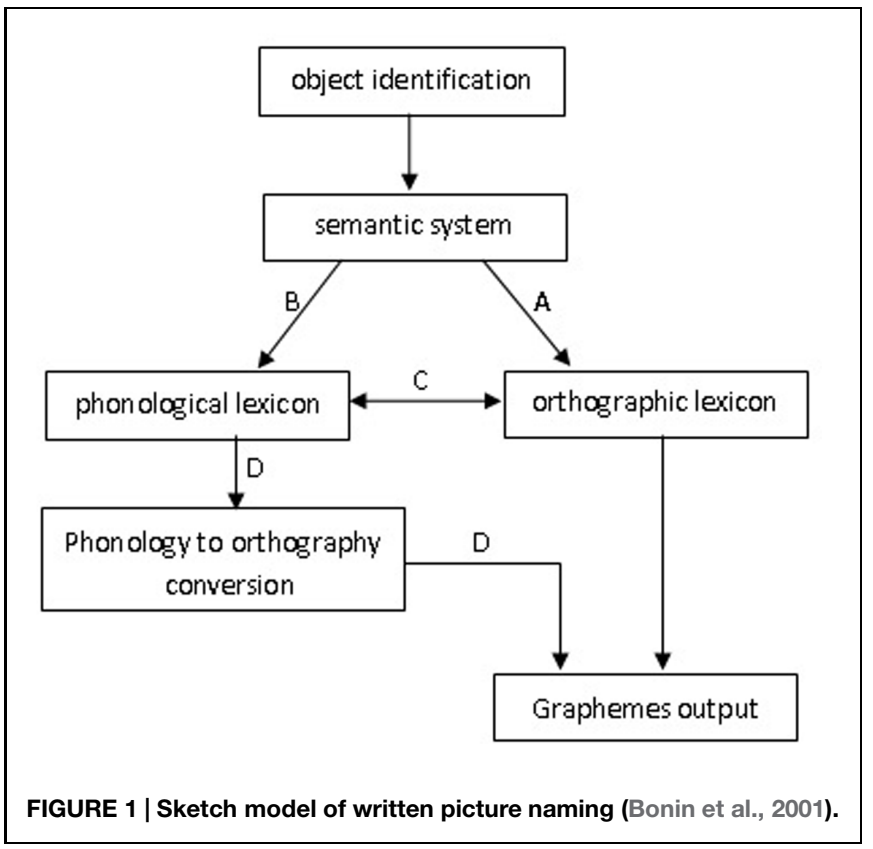

activated from the semantic system (by link A and link B in Figure 1, respectively) and map directly onto one another (by link $\mathrm{C}$ in Figure 1). By contrast, the strong version does not acknowledge the links between two lexicons and assumes that phonology may influence orthographic output by a sublexical route (link D). Bonin et al.'s (2001) model suggests that there are lexical (link C) and sublexical (link D) routes from phonology to orthography in written production.

Relatively few empirical studies have addressed the relationship between phonological and orthographic codes with chronometric tasks, and their results have been inconsistent. A few studies demonstrated that phonological codes indeed influence writing (e.g., Bonin et al., 2001; Zhang and Damian, 2010; Afonso and Álvarez, 2011; Damian et al., 2011). Bonin et al. (2001) manipulated the consistency of phonology-orthography mappings at the lexical and sublexical levels in healthy participants to identify the potential effect of phonological codes in written picture naming. The heterographic homophones of picture names carry phonology-to-orthography inconsistencies at both the lexical and sublexical levels. For example, the picture name cygne (meaning swan in French) and the word signe (meaning sign in French) are heterographic homophones. The cygne was matched with a control picture name, which has no heterographic homophone. Hence, the item in the control condition was consistent, while the target picture name was inconsistent at the lexical level. The inconsistency at the sublexical level was defined at the level of the onset, vocalic and coda units as well as the level of onset plus vowel and vowel plus coda units. Word-initial inconsistencies at the sublexical level were found to affect writing latencies: picture names with inconsistent phono-orthographic mapping (e.g., oeil in French) were written more slowly than those with consistent phono-orthographic mapping (e.g., ongle in French), whereas no difference was found when consistency was manipulated at the lexical level. This finding further suggests 
that phonology affects orthographic encoding primarily via a sublexical route.

Zhang and Damian (2010) used a written PWI task to examine the role of phonology in English speakers. Distractors were orthographically and phonologically (OP) related (e.g., picture name: "hand"; distractor: "sand"), orthographically (O) related (e.g., "hand" and "wand"), or unrelated. Zhang and Damian found an exclusive effect of phonology at an stimulus of onset asynchrony (SOA) of $0 \mathrm{~ms}$ (OP minus $\mathrm{O}$ ) and orthographic priming at an SOA of $100 \mathrm{~ms}$, indicating that phonological codes constrain access to orthographic codes at an early stage in written production. By contrast, Bonin et al. (1998b) did not find evidence for the role of phonology in written production in French, which was inconsistent with the findings for English, and this discrepancy casts doubt on the role of phonology in written production.

Evidence for phonological constraints largely stems from studies conducted with alphabetic scripts. This finding is perhaps not surprising for writing systems with alphabetic scripts, in which phonological and orthographic codes are closely interrelated and the relationships between phonology and orthography are quasisystematic. In non-alphabetic scripts, however, it is less obvious why orthographic retrieval should be affected by phonological codes. Because orthography and phonology are largely dissociated in non-alphabetic scripts, such as Chinese, the orthographic and phonological effects can be appropriately separated from one another in such scripts with an appropriate manipulation. With a PWI task, Qu et al. (2011) manipulated the distractors that were OP related, phonologically $(\mathrm{P})$ related, or unrelated with picture names and with SOAs: 0, 100, and $200 \mathrm{~ms}$. Priming effects were found for both types of related distractors relative to unrelated distracters at 0 and $100 \mathrm{~ms} \mathrm{SOA}$, whereas priming from the $\mathrm{P}$ related distractors was restricted to $0 \mathrm{~ms}$ SOA. These results thus provide evidence that phonological codes are activated rapidly and constrain orthographic output in a non-alphabetic script.

However, there were two potential problems in $\mathrm{Qu}$ et al.'s (2011) study. First, the degrees of phonological overlapping are not matched in the OP related and $\mathrm{P}$ related conditions. Most Chinese characters contain a so-called "phonetic radical," i.e., part of a character that indicates how the character as a whole is pronounced. However, the phonetic radical does not always indicate the correct pronunciation of a Chinese character. In $\mathrm{Qu}$ et al.'s (2011) study, the phonetic radicals of 15 OP related and 1 $P$ related distractors among 20 distractors can indicate the pronunciation of entire characters [see Qu et al.'s (2011) material sets for details; e.g., picture name: “樱桃, /ying1tao2/, cherry in English; the OP distractor: “缨子”/ying1zi/, tassel]. This issue may result in a larger facilitation effect in the OP condition but a smaller facilitation effect in the $\mathrm{P}$ condition. Zhao, La Heij and Schiller's (2012) finding provides evidence for this possibility: a $72-\mathrm{ms}$ phonological facilitation effect at SOA $=0 \mathrm{~ms}$ was reduced to $38 \mathrm{~ms}$ when phonetic radicals were avoided, reflecting that whether the phonetic radical of a character indicates the pronunciation of the entire character affects the magnitude of the phonological effect. Qu et al. (2011) observed a significant $\mathrm{OP}$ effect $(31 \mathrm{~ms})$ in the OP condition and a non-significant $\mathrm{P}$ effect $(15 \mathrm{~ms})$ at SOA $=0 \mathrm{~ms}$, and they inferred that the OP effect is orthographic in nature. Because of the aforementioned confounding factor, it is difficult to conclude that the mixed OP effect originates from orthographically relatedness or phonologically relatedness or from the combination of both. Second, the O related condition was not included in Qu et al.'s (2011) study, and the authors inferred the activation of orthographic codes by comparing the OP effect and the P effect. Our experiment design will avoid these problems.

In the domain of written production, a simple view is proposed on the basis of psycholinguistic and cognitive neuropsychological studies of speech production. Although the spoken and written language production systems may share some processing levels, they also have some specific components (Bonin et al., 1998a). In picture name speaking and writing, a structural level and a semantic level are common, whereas there may be a phonological lexeme level in spoken language but an orthographic lexeme level in handwritten language (Ellis, 1982, 1988; Caramazza and Hillis, 1990; Bonin et al., 1998b). Furthermore, there is a lexical link between phonological and orthographic lexemes (Ellis, 1988; Miceli et al., 1997, 1999; Bonin et al., 1998b). The connection between phonology and orthography is bi-directional: phonological information may serve as input for the articulation process in spoken production, and orthographic information may serve as input for the graphic output process in written production. In the literature on written production, a typical research approach is to compare the processes of written and spoken production to find the dissociation or association between them (i.e., Miceli et al., 1997; Rapp et al., 1997; Bonin et al., 1998a; Damian et al., 2011).

In the present study, we manipulated the OP related, $\mathrm{O}$ related, $P$ related, and unrelated distractor words with target names in a PWI task. The SOA interval between the picture and distractor was also varied. The SOAs of $-100 \mathrm{~ms}$ (distractor onset before pictures), $0 \mathrm{~ms}$, and $+100 \mathrm{~ms}$ (distractor onset after pictures) were used (Qu et al., 2011). Manipulating the onset of the distractor relative to that of the picture allows us to tap into successive processing stages as a response is being prepared (e.g., Schriefers et al., 1990; Zhang and Damian, 2010; Qu et al., 2011). It is acceptable that negative SOA taps into the early processing stage, while positive SOA taps into the relatively later stage in the PWI task. The participants were asked to write (Experiments 1 and 2) or speak (Experiment 3 ) the picture names. This approach allows us to directly compare the time course of orthographic and phonological codes in speaking and writing experiments as well as to investigate the contribution of orthographic and phonological codes in written production. We would put emphasis on the relative temporal sequences of orthographic and phonological effects in writing and speaking. Previous studies of Chinese spoken production demonstrated that orthographic and phonological effects are independent (Bi et al., 2009; Zhang and Weekes, 2009; Zhang et al., 2009; Zhao et al., 2012), and the former arises earlier than (Zhang and Weekes, 2009; Zhang et al., 2009) or simultaneously with (Zhao et al., 2012) the latter. Therefore, we predict a time pattern for the $\mathrm{O}$ effect and the $\mathrm{P}$ effect that is similar to that found for Chinese spoken production. 
Concerning the comparison between written and spoken production, according to the obligatory phonological mediation hypothesis, written production depends on spoken production; thus, we would expect phonological activation to arise prior to orthographic activation in speaking and writing. According to the orthographic autonomy hypothesis, written production is not dependent on spoken production, and orthographic information must be activated in writing and prior to or simultaneously with phonological activation because of the connection between phonological and orthographic lexicons.

\section{Experiment 1}

\section{Method \\ Participants}

Twenty-four students (11 males, average age 23.0 years, age range $19-28$ years) participated in the study and were paid approximately $\$ 3$. All students were native Mandarin Chinese speakers with normal or corrected-to-normal vision.

\section{Materials}

Fourteen target pictures with monosyllabic names were selected from Zhang and Yang's (2003) picture database. All pictures had monosyllabic names, with an average lexical frequency of 41.84 per million (Beijing Language Institute, 1986) and an average stroke number of 10. Each picture was paired with three types of form-related monosyllabic distractor words: (1) an orthographically related $(\mathrm{O})$ but phonologically dissimilar word that shared the phonetic radical but no syllable with the picture name [i.e., 狐 (fox, /hu2/) - 吸 ( cally related $(\mathrm{P})$ but orthographically dissimilar word that shared the syllable but no radical with the picture name [i.e., 狐 - 壸 (pot, /hu2/)], and (3) an orthographically plus phonologically related word (OP) that shared the phonetic radical and the syllable with the picture name [i.e., 狐 - 弧 $(\underline{\operatorname{arc}}, / \mathrm{hu} 2 /)$ ]. For the phonological overlap in the OP and O distractors, both shared the same syllables with target names. For the orthographic overlap in the OP and O distractors, both shared the same phonetic radicals with targets, which are not the first radicals of the target picture names. Importantly, the phonetic radicals of the OP related and $\mathrm{P}$ distractor words cannot indicate the pronunciation of the entire characters, and the potential influence of phonetic radicals is excluded (see also Zhao et al., 2012).

The distractors in each condition were then recombined with the picture names to form each corresponding unrelated condition. Semantic or associative relationships between the picture names and distractors were avoided in all combinations. Across three distractor type conditions, the distractor words were statistically matched in the number of strokes and lexical frequency based on normative information reported in the database of the Modern Chinese Frequency Dictionary (Beijing Language Institute, 1986).

\section{Design}

The experimental design included Relatedness (related vs. unrelated), Distractor Type (O, P, and OP related), and SOA ( $-100,0$, and $100 \mathrm{~ms}$ ) as within-participants and within-items factors. For each participant, each picture was displayed under each relatedness and SOA condition, resulting in 342 combinations. Trials were blocked by SOA, and the order in which the participants encountered the SOA blocks varied according to a Latin square design. A new pseudorandom sequence was generated for each participant and each block, with the constraint that neither the targets nor the distractors were repeated on consecutive trials.

\section{Apparatus}

The experiment was performed using E-Prime Professional Software (Version 1.1). The participants were seated in a quiet room $\sim 70 \mathrm{~cm}$ from a 19-inch LED computer screen. Written responses were recorded with a WACOM Intuos A4 graphic tablet with a WACOM inking digitizer pen.

\section{Procedure}

The participants were tested individually. They sat in a quiet room at a comfortable viewing distance in front of the computer. The participants were first asked to familiarize themselves with the experimental stimuli by viewing each picture for $3000 \mathrm{~ms}$ with the picture name printed below each picture. Then, eight warm-up trials and 114 experimental trials were administered for each SOA block. Each trial involved the following sequence: a fixation point $(+)$ presented in the middle of the screen for $500 \mathrm{~ms}$, followed by a blank screen for $500 \mathrm{~ms}$. Subsequently, the first stimulus (either the distractor or the target) appeared, followed by the appearance of the second stimulus. For SOA $=0 \mathrm{~ms}$, the target and distractor appeared simultaneously.

The distractor words were presented in 25-Song font, centrally superimposed on the target pictures. The pictures were displayed at the bottom of the screen to reduce the participants' head and eye movements as they wrote the picture names. The participants were asked to write down picture names as quickly and accurately as possible. During the experiment, the participants were instructed to hover the stylus just above the corresponding line on the sheet in anticipation of the response, so that the response would not require an arm movement. An inter-trial interval of $3500 \mathrm{~ms}$ concluded each trial. The experiment required $\sim 40 \mathrm{~min}$ in total.

\section{Results}

Data from incorrect responses (1.04\%) naming latencies longer than $2000 \mathrm{~ms}$ or shorter than $300 \mathrm{~ms}(1.09 \%)$ and those deviating by more than $2.5 \mathrm{SD}$ from the cell mean (1.50\%) were removed from all analyses. The remaining data were used in the subsequent statistical analysis. Table 1 presents the mean latencies and error percentages for Relatedness, Type of Relatedness, and SOA.

We used the lmer program of the lme4 package for estimated fixed effects and parameter estimation of the LMM (Bates, 2005; Baayen et al., 2008). The free software $\mathrm{R}$ was used ( $\mathrm{R}$ Development Core Team, 2009). The data were analyzed using a linear mixed-effects model that included the fixed effects of Relatedness (related vs. unrelated), Distractor Type, and SOA, as well as by-participant and by-item random intercepts. Models were fit to the data using restricted maximum likelihood estimation, which seeks to find the parameter values that make 
TABLE 1 | Mean response latencies (RT in milliseconds) and mean error percentages (PE) in Experiment 1.

\begin{tabular}{|c|c|c|c|c|c|c|}
\hline \multirow[t]{3}{*}{ Condition } & \multicolumn{6}{|c|}{ SOA } \\
\hline & \multicolumn{2}{|c|}{-100} & \multicolumn{2}{|c|}{0} & \multicolumn{2}{|c|}{+100} \\
\hline & $\mathbf{R T}$ & PE & RT & PE & RT & PE \\
\hline OP_R & 957 & 0.60 & 913 & 0.60 & 923 & 1.19 \\
\hline OP_U & 1007 & 1.79 & 961 & 1.19 & 967 & 0.90 \\
\hline Effect & $+50^{* * *}$ & & $+48^{* * *}$ & & $+44^{* * *}$ & \\
\hline O_R & 960 & 0.89 & 900 & 1.19 & 936 & 1.19 \\
\hline O_U & 1001 & 0.60 & 933 & 0.89 & 971 & 1.49 \\
\hline Effect & $+41^{*}$ & & $+33^{*}$ & & $+35^{*}$ & \\
\hline P_R & 977 & 1.49 & 943 & 0.89 & 946 & 1.19 \\
\hline P_U & 988 & 1.19 & 961 & 1.19 & 972 & 0.30 \\
\hline Effect & +11 & & +18 & & $+26^{*}$ & \\
\hline
\end{tabular}

${ }^{*} p<0.05 ;{ }^{* * *} p<0.001$.

$\mathrm{OP}=$ orthographically plus phonologically related; $\mathrm{O}=$ orthographically related but phonologically unrelated; $P=$ phonologically related but orthographically unrelated; $R=$ Related; $U=$ unrelated.

the model's predicted values most similar to the observed values. Model fitting was performed by initially specifying a model that included only the random factors (participants and items) and was then enriched by subsequently adding the fixed factors Relatedness, Distractor Type and SOA one by one, followed by the interaction between Relatedness and Distractor Type, the interaction between Relatedness and SOA, the interaction of Distractor Type and SOA, and the 3-way interaction among the three fixed variables one by one. The best-fitting model was defined to be the most complex model that significantly improved the fit over the previous model. If adding a fixed factor or an interaction among factors did not significantly improve the fit, then this result indicates that those factors do not significantly influence the dependent variables (i.e., naming latencies).

The results are reported for the best-fitting models. Latencies and errors were analyzed separately for Relatedness, Distractor Type and SOA. For latencies, the best-fitting model included SOA, Relatedness, Distractor Type, and the interaction between Relatedness and Distractor Type. Adding the interaction between SOA and Distractor Type, $\chi^{2}(4,5824)=3.53$, $p=0.47$, the interaction between SOA and Relatedness, $\chi^{2}(2,5824)=0.15, p=0.93$, and the interaction among three variables, $\chi^{2}(4,5824)=0.72, p=0.95$, did not significantly improve the fit. Table 2 summarizes the fixed effects of the best model fit.

We followed the significant interaction between Relatedness and Distractor Type with separate contrasts. First, we tested for relatedness effects (i.e., unrelated vs. related) separately for each of three types of relatedness. For the OP condition, the results showed that the effects of relatedness differed significantly from one another at $-100 \mathrm{~ms} \mathrm{SOA}, t(639)=4.27, p<0.001,0 \mathrm{~ms}$ $\mathrm{SOA}, t(652)=3.58, p<0.001$, and $+100 \mathrm{~ms} \mathrm{SOA}, t(648)=4.42$, $p<0.001$. For the $\mathrm{O}$ condition, the results showed that the effects
TABLE 2 | Summary of fixed effects in the linear mixed-effects model for onset latencies in Experiment 1.

\begin{tabular}{lcccc}
\hline Effects & Estimate & SE & $\boldsymbol{t}$ & $\boldsymbol{P r}(>|\boldsymbol{t}|)$ \\
\hline (Intercept) & 958.47 & 35.61 & 26.92 & 0.0000 \\
SOA: 0 ms & -47.51 & 5.69 & -8.35 & 0.0000 \\
SOA: $100 \mathrm{~ms}$ & -33.25 & 5.69 & -5.84 & 0.0000 \\
Orthographic relatedness & 8.84 & 8.00 & 1.10 & 0.2696 \\
Phonological relatedness & 27.04 & 8.00 & 3.38 & 0.0007 \\
Unrelated & 52.06 & 8.05 & 6.47 & 0.0000 \\
Unrelated:Orthographically & -25.50 & 11.38 & -2.24 & 0.0251 \\
Unrelated:Phonologically & -33.15 & 11.38 & -2.91 & 0.0036 \\
\hline
\end{tabular}

of relatedness differed significantly from one another at $-100 \mathrm{~ms}$ SOA, $t(647)=2.11, p<0.05,0 \mathrm{~ms}$ SOA, $t(647)=2.38, p<0.05$, and $+100 \mathrm{~ms} \mathrm{SOA}, t(647)=2.32, p<0.05$. By contrast, for the $\mathrm{P}$ condition, the results showed that the effects of relatedness differed significantly from one another at $100 \mathrm{~ms}$ SOA, $t(650)=2.07, p<0.05$, but not at $-100-\mathrm{ms} \mathrm{SOA}, t(646)=0.98$, $p=0.32$, and $0 \mathrm{~ms} \mathrm{SOA}, t(648)=1.35, p=0.19$.

Finally and most importantly, we assessed the degree of additivity between orthographic and phonological relatedness using a formula (see Balota and Paul, 1996; Melinger and Abdel Rahman, 2004 for a similar logic) that indicates the OP effect on the lefthand side (related minus unrelated) and the sum of the $\mathrm{O}$ and $\mathrm{P}$ effects on the right-hand side.

$\mathrm{OP}$ effect $=\mathrm{O}$ effect $+\mathrm{P}$ effect

If the effects of orthographic and phonological effects are additive, then the two sides of the equation should be statistically equal; if the effects interact, then the two sides of the equation should deviate from zero. Under the assumption that orthographic and phonological variables do not interact, their respective effects should additively summate. For instance, at SOA $=-100 \mathrm{~ms}$, Table 1 shows an orthographic effect of $41 \mathrm{~ms}$ (significant) and a phonological effect of $11 \mathrm{~ms}$ (insignificant). An additive relationship would predict an effect of $52 \mathrm{~ms}(41+$ $11 \mathrm{~ms}$ ) for the OP condition. Empirically, the observed OP effect is $50 \mathrm{~ms}$, which is numerically close to the prediction derived from additivity.

We tested this contrast via a coding of $[-1,1,-1,1,1,-1]$ across the orthographically unrelated and related, phonologically related and unrelated, and orthographically plus phonologically unrelated and related cells. This analysis did not return significant results for any of the SOA levels [all $F s(1,23) \leq 0.78, p \geq 0.39$ ], suggesting that orthographic and phonological relatedness did not interact at the three SOAs. Bayesian analysis with the method suggested by Masson (2011) resulted in a Bayes factor of 5.20 with $p \mathrm{BIC}\left(\mathrm{H}_{0} \mid \mathrm{D}\right)=0.77$ and $p \mathrm{BIC}\left(\mathrm{H}_{1} \mid \mathrm{D}\right)=0.23$ at $-100 \mathrm{~ms}$ SOA, 4.88 with $p \mathrm{BIC}\left(\mathrm{H}_{0} \mid \mathrm{D}\right)=0.83$ and $p \mathrm{BIC}\left(\mathrm{H}_{1} \mid \mathrm{D}\right)=0.17$ at $0 \mathrm{~ms}$ SOA, and of 4.90 with $p \mathrm{BIC}\left(\mathrm{H}_{0} \mid \mathrm{D}\right)=0.83$ and $p \mathrm{BIC}\left(\mathrm{H}_{1} \mid \mathrm{D}\right)=0.17$ at $+100 \mathrm{~ms} \mathrm{SOA}$, which constitutes "positive" evidence for the null hypothesis (i.e., an additive pattern between orthographic and phonological effects) according to the classification suggested by Raftery (1999).

A parallel analysis of variance conducted on the errors showed that none of the models that included SOA, Relatedness, 
Distractor Type, or two-way or three-way interactions improved the fit, $\chi^{2} \leq 2.64, p \geq 0.39$.

\section{Discussion}

The results showed that the $\mathrm{OP}$ related and $\mathrm{O}$ related distractors reliably facilitated written production at $-100,0$, and $+100 \mathrm{~ms}$ SOAs, while the $\mathrm{P}$ related distractors facilitated written production at $+100 \mathrm{~ms}$ SOA. Critically, the difference between the $\mathrm{OP}$ related effect and the $\mathrm{O}$ related effect was not significant at $-100 \mathrm{~ms}$ SOA. At $-100 \mathrm{~ms}$ SOA, the magnitude of the OP effect $(50 \mathrm{~ms})$ was significantly larger than that of the $\mathrm{P}$ effect (11 ms) but was not larger than the magnitude of the $\mathrm{O}$ effect (41 ms), reflecting that the OP effect was primarily orthographic, not phonological. Furthermore, the formula analysis indicates that the $\mathrm{O}$ effect and the $\mathrm{P}$ effect did not interact but rather exerted an additive effect. The present finding shows that phonology is not accessed earlier than orthography in Chinese written production. By contrast, Qu et al. (2011) found that phonology is activated before orthography (see also Zhang and Damian, 2010). Therefore, our finding is not consistent with previous data. To examine the reliability of our findings, we aim to replicate the findings of Experiment 1 in Experiment 2.

\section{Experiment 2}

\section{Method \\ Participants}

Twenty-four students (10 males, average age 22.2 years, age range 19-26 years) from the same pool participated in the experiment and were paid approximately $\$ 6$.

\section{Materials}

Twenty-five black-and-white pictures with monosyllabic names were selected, including 14 target pictures and 11 fillers. There were five semantic categories (animals, tools, housewares, weapons, and music instruments), and each category consisted of five pictures. We deleted three pictures used in experiment 1 (烟, cigarette, /yan1/; 斧, ox, /fu3/, and 桃, peach, /tao2/) because of the phoneme overlap between phonetic radicals and entire character pronunciation, and we added three other target pictures (锅, pot, /guo1/, 瓶, bottle, /ping2/, and 箭, arrow, /jian4/). Similar to Experiment 1, each target picture was paired with three types of distractor words (OP, O, and $\mathrm{P}$ ) and then recombined to form corresponding unrelated conditions. Each filler picture was also paired with three unrelated distracter words, and the distractors in each condition were then recombined with the picture names to form other unrelated conditions.

The design, apparatus, procedures, and other aspects of the materials were identical to those used in Experiment 1.

\section{Results}

Data for target pictures were analyzed. Incorrect responses and other responses such as "well" or hesitations (0.79\%), naming latencies longer than $2000 \mathrm{~ms}$ or shorter than $300 \mathrm{~ms}$ (1.04\%), and those deviating by more than 2.5 SD from the cell means $(2.60 \%)$ were removed from all analyses. The remaining data were used in the subsequent statistical analysis. Table 3 presents the mean latencies and error percentages for Relatedness, Distractor Type, and SOA.

The results are reported for the best-fitting models. Latencies and errors were analyzed separately for Relatedness, Distractor Type, and SOA. For latencies, the best-fitting model included SOA, Relatedness, and the interaction between Relatedness and Distractor Type. Adding Distractor Type, $\chi^{2}(2,5775)=1.78$, $p=0.40$, the interaction between SOA and Distractor Type, $\chi^{2}(4,5775)=5.35, p=0.25$, the interaction between SOA and Relatedness, $\chi^{2}(2,5775)=1.81, p=0.40$, and the interaction among three variables, $\chi^{2}(4,5775)=0.22, p=0.99$, did not significantly improve the fit. Table 4 summarizes the fixed effects of the best-fitting model.

A follow-up analysis similar to that used in Experiment 1 was conducted. For the OP condition, the results showed that the effects of relatedness differed significantly from one another at $-100 \mathrm{~ms} \mathrm{SOA}, t(653)=3.75, p<.001,0 \mathrm{~ms} \mathrm{SOA}, t(640)=4.34$, $p<0.001$, and $+100 \mathrm{~ms} \mathrm{SOA}, t(634)=4.51, p<0.001$. For the $\mathrm{O}$ condition, the results showed that the effects of relatedness differed significantly from one another at $-100 \mathrm{~ms}$ SOA, $t(647)=2.34, p<0.05,0 \mathrm{~ms} \mathrm{SOA}, t(639)=3.65, p<0.001$, and $+100 \mathrm{~ms}$ SOA, $t(633)=3.92, p<0.001$. For the $\mathrm{P}$ condition, the results showed that the effects of relatedness did not

\begin{tabular}{|c|c|c|c|c|c|c|}
\hline \multirow[t]{3}{*}{ Condition } & \multicolumn{6}{|c|}{ SOA } \\
\hline & \multicolumn{2}{|c|}{-100} & \multicolumn{2}{|c|}{0} & \multicolumn{2}{|c|}{+100} \\
\hline & $\mathbf{R T}$ & PE & RT & PE & $\mathbf{R T}$ & PE \\
\hline OP_R & 863 & 0 & 850 & 0 & 834 & 0.30 \\
\hline OP_U & 897 & 0.60 & 898 & 0.89 & 873 & 0.60 \\
\hline Effect & $+34^{* * *}$ & & $+48^{* * *}$ & & $+39^{* * *}$ & \\
\hline O_R & 870 & 0 & 864 & 0 & 836 & 0.60 \\
\hline O_U & 896 & 0.89 & 893 & 0.60 & 874 & 0.60 \\
\hline Effect & $+26^{*}$ & & $+29^{* * * *}$ & & $+38^{* * *}$ & \\
\hline P_R & 875 & 0 & 860 & 0 & 868 & 0.60 \\
\hline P_U & 886 & 0.89 & 881 & 0.30 & 877 & 0.60 \\
\hline Effect & +11 & & $+21^{\dagger}$ & & +9 & \\
\hline
\end{tabular}

TABLE 4 | Summary of fixed effects in the linear mixed-effects model for onset latencies in Experiment 2.

\begin{tabular}{lclcl}
\hline Effects & Estimate & SE & $\boldsymbol{t}$ & $\boldsymbol{P r}(>|\boldsymbol{t}|)$ \\
\hline Intercept) & 862.74 & 35.15 & 24.54 & 0.0000 \\
SOA: 0 ms & -3.80 & 4.56 & -0.83 & 0.4048 \\
SOA: $100 \mathrm{~ms}$ & -15.37 & 4.57 & -3.37 & 0.0008 \\
Unrelated & 42.58 & 6.45 & 6.60 & 0.0000 \\
Unrelated:Orthographically & -0.03 & 6.49 & -0.01 & 0.1788 \\
Unrelated:Phonologically & -8.51 & 6.47 & -1.32 & 0.9960 \\
Related:Orthographically & 8.64 & 6.43 & 1.35 & 0.0022 \\
Related:Phonologically & 19.74 & 6.43 & 3.07 & 0.1881
\end{tabular}


differ significantly from one another at $0 \mathrm{~ms} \mathrm{SOA}, t(642)=0.98$, $p=0.33,0 \mathrm{~ms}$ SOA, $t(644)=1.70, p=0.09$, and $+100 \mathrm{~ms} \mathrm{SOA}$, $t(643)=1.30, p=0.19$.

We again tested the contrasting effects via a coding of $[-1$, $1,-1,1,1,-1]$ across the orthographically unrelated and related, phonologically related and unrelated, and orthographically plus phonologically unrelated and related cells. This analysis did not return significant results for any SOA levels [all $F s(1,23) \leq 0.12, p \geq 0.49$ ], suggesting that orthographic and phonological relatedness did not interact. Bayesian analysis as performed in Experiment 1 resulted in a Bayes factor of 4.52 with $p \mathrm{BIC}\left(\mathrm{H}_{0} \mid \mathrm{D}\right)=0.82$ and $p \mathrm{BIC}\left(\mathrm{H}_{1} \mid \mathrm{D}\right)=0.18$ at $-100-\mathrm{ms}$ $\mathrm{SOA}$, of 4.10 with $p \mathrm{BIC}\left(\mathrm{H}_{0} \mid \mathrm{D}\right)=0.80$ and $p \mathrm{BIC}\left(\mathrm{H}_{1} \mid \mathrm{D}\right)=0.20$ at $0-\mathrm{ms} \mathrm{SOA}$, and of 3.76 with $\mathrm{pBIC}\left(\mathrm{H}_{0} \mid \mathrm{D}\right)=0.79$ and $p \mathrm{BIC}\left(\mathrm{H}_{1} \mid \mathrm{D}\right)=0.21$ at $+100-\mathrm{ms} \mathrm{SOA}$, which constitutes "positive" evidence for the null hypothesis of additive effects of orthographic and phonological relatedness (Raftery, 1999).

A parallel analysis of variance conducted on the errors showed that none of the models that included SOA, Relatedness, Distractor Type, or two-way or three-way interactions improved the fit, $\chi^{2} \leq 4.47, p \geq 0.11$.

\section{Discussion}

The results showed that the $\mathrm{OP}$ related and $\mathrm{O}$ related distractors reliably facilitated written production at $-100,0$, and $+100 \mathrm{~ms}$ SOAs, and these findings replicated the results of Experiment 1 , while the $\mathrm{P}$ related distractors produced a marginally significant facilitation effect at $0 \mathrm{~ms}$ SOA. As in the first experiment, the difference between the OP related effect and the $\mathrm{O}$ related effect was not significant, whereas the difference between the OP effect and the $\mathrm{P}$ effect was significant, indicating that the OP effect was primarily orthographic, not phonological. Statistical tests on this formula also indicated that orthographic relatedness and phonological relatedness did not interact, which is perfectly consistent with the findings in Experiment 1. Experiments 1 and 2 hence provide converging evidence for an additive pattern of orthographic and phonological relatedness and indicate that phonology is not accessed earlier than orthography in Chinese written production.

There were some important divergences in Experiments 1 and 2. The magnitude of the OP effect and the O effect were comparable in both experiments. By contrast, there were significant phonological effects $(26 \mathrm{~ms})$ at $+100 \mathrm{~ms}$ in Experiment 1 versus a marginally significant effect $(21 \mathrm{~ms})$ at $0 \mathrm{~ms}$ in Experiment 2 . The absence of the $\mathrm{P}$ effect may result from the relatively larger picture sets: there were 14 target pictures in the first experiment and 25 in the second experiment. In both experiments, each target picture was presented and named 18 times by each participant, which is a common manipulation in studies using the PWI paradigm. The classic semantic interference and form-related facilitation cannot be eliminated by repetition in spoken responses, so it is usually acceptable in studies and not perceived as problematic. However, Roelofs (2001) proposed that when target names are repeated many times, causing participants to establish a response set in memory, even the number of target names slightly exceeds the short-term memory span, which may include 12-16 responses. Therefore, it was easier to establish a response set for 14 items in Experiment 1 than for 25 items in Experiment 2. However, the percentage of phonologically related distracters was $16.7 \%$ in Experiment 1 compared with 9.33\% in Experiment 2. Therefore, it could be argued that the results of Experiment 2 underestimate the effects of phonology in handwriting for those two reasons. Although we acknowledge this possibility, it should be noted that the situations of OP related and $\mathrm{O}$ related conditions were identical to the $\mathrm{P}$ related condition, but the $\mathrm{OP}$ effect and the $\mathrm{O}$ effect were comparable in both experiments; only the $\mathrm{P}$ effect was absent in Experiment 2. Therefore, our results indicate that the phonological facilitation effect was vulnerable to the number of picture sets and the percentage of phonologically related trials in total, while the orthographic facilitation effect was stable and reliable. Hence, the influence of phonological codes in handwritten production may not be mandatory and universal.

\section{Experiment 3}

In the literature, cognitive neuropsychological studies have reported an experimental dissociation in writing and speaking (Miceli et al., 1997; Rapp et al., 1997). Researchers have also proposed written production models on the basis of speech production. Therefore, we conducted a speaking experiment using the same stimuli and experimental paradigm. This approach allows us to compare the time course of orthographic and phonological codes in speaking and writing in normal adults. As mentioned in the introduction, such a comparison would provide relevant evidence for the argument of the phonological mediation hypothesis and the orthography autonomy hypothesis.

\section{Method \\ Participants}

Six months after Experiment 1 was conducted, the same 22 participants in Experiment 1 returned and participated in Experiment 3 , and they reported that they had little memory of Experiment 1. Two more participants were recruited from the same pool of participants. All participants were paid approximately $\$ 4$.

The materials, design, apparatus, and procedure were identical to those used in Experiment 1, except that the participants were asked to name the target aloud as quickly and accurately as possible, and naming latencies were measured from target onset using a voice-key connected with the computer via a PST Serial Response Box. The inter-trial interval was $1500 \mathrm{~ms}$, and the experiment took $\sim 30 \mathrm{~min}$ in total.

\section{Results}

Data from incorrect responses (1.49\%), naming latencies longer than $1500 \mathrm{~ms}$ or shorter than $200 \mathrm{~ms}$ (1.39\%), and those deviating by more than 2.5 SD from the cell mean $(2.96 \%)$ were removed from all analyses. The remaining data were used in the subsequent statistical analysis. Table 5 presents the mean latencies and error percentages for Relatedness, Distractor Type, and SOA.

The results are reported for the best-fitting models. Latencies and errors were analyzed separately. For latencies, the bestfitting model included SOA, Relatedness, the interaction between 
TABLE 5 | The mean latencies and error percentages for Relatedness, Distractor Type, and SOA in Experiment 3.

\begin{tabular}{|c|c|c|c|c|c|c|}
\hline \multirow[t]{3}{*}{ Condition } & \multicolumn{6}{|c|}{ SOA } \\
\hline & \multicolumn{2}{|c|}{-100} & \multicolumn{2}{|c|}{0} & \multicolumn{2}{|c|}{+100} \\
\hline & RT & PE & $\mathbf{R T}$ & PE & RT & PE \\
\hline OP_R & 622 & 0.60 & 601 & 0 & 629 & 1.19 \\
\hline OP_U & 695 & 0.89 & 698 & 1.79 & 681 & 2.38 \\
\hline Effect & $+73^{* * * *}$ & & $+97^{* * * *}$ & & $+52^{* * * *}$ & \\
\hline O_R & 643 & 0.30 & 613 & 0.89 & 632 & 0.89 \\
\hline O_U & 695 & 0.60 & 680 & 0.19 & 667 & 0.89 \\
\hline Effect & $+52^{* * * *}$ & & $+67^{* * * *}$ & & $+35^{* * * *}$ & \\
\hline P_R & 650 & 0.30 & 631 & 0.60 & 630 & 0.30 \\
\hline P_U & 678 & 1.79 & 685 & 2.38 & 680 & 2.38 \\
\hline Effect & $+28^{* * * *}$ & & $+54^{* * * *}$ & & $+50^{* * * *}$ & \\
\hline
\end{tabular}

$* * * * p<.0001$.

SOA and Distractor Type, the interaction between Relatedness and Distractor Type, the interaction between Relatedness and Distractor Type, and the three-way interaction. Adding Distractor Type did not significantly improve the fit, the interaction between SOA and Distractor Type, $\chi^{2}(2,5720)=2.88$, $p=0.24$. Table 6 summarizes the fixed effects of the best-fitting model fit.

An analysis similar to that performed in Experiment 1 was conducted. For the OP condition, the results showed that the effects of relatedness differed significantly from one another at $-100 \mathrm{~ms} \mathrm{SOA}, t(638)=10.34, p<0.0001,0 \mathrm{~ms}$ SOA, $t(641)=13.98, p<0.0001$, and $+100 \mathrm{~ms} \mathrm{SOA}, t(626)=7.10$,

TABLE 6 | Summary of fixed effects in the linear mixed-effects model for onset latencies in Experiment 3.

\begin{tabular}{|c|c|c|c|c|}
\hline Effects & Estimate & SE & $t$ & $\operatorname{Pr}(>|t|)$ \\
\hline (Intercept) & 700.15 & 18.84 & 37.15 & 0.0000 \\
\hline SOA2 & 2.97 & 7.59 & 0.39 & 0.6959 \\
\hline SOA3 & -10.946 & 7.62 & -1.44 & 0.1508 \\
\hline related2 & -75.28 & 7.502 & -10.04 & 0.0000 \\
\hline SOA1:type2 & -0.408 & 7.55 & -0.05 & 0.9572 \\
\hline SOA2:type2 & -20.97 & 7.61 & -2.75 & 0.0060 \\
\hline SOA3:type2 & -20.218 & 7.57 & -2.67 & 0.0076 \\
\hline SOA1:type3 & -17.06 & 7.62 & -2.24 & 0.0251 \\
\hline SOA2:type3 & -12.74 & 7.61 & -1.67 & 0.0944 \\
\hline SOA3:type3 & -4.364 & 7.63 & -0.57 & 0.5673 \\
\hline SOA2:related2 & -25.85 & 10.60 & -2.44 & 0.0148 \\
\hline SOA3:related2 & 17.82 & 10.66 & 1.67 & 0.0946 \\
\hline related2:type2 & 21.40 & 10.60 & 2.02 & 0.0434 \\
\hline related2:type3 & 44.39 & 10.64 & 4.17 & 0.0000 \\
\hline SOA2:related2:type2 & 11.41 & 15.00 & 0.76 & 0.4468 \\
\hline SOA3:related2:type2 & 2.55 & 15.01 & 0.17 & 0.8650 \\
\hline SOA2:related2:type3 & -0.48 & 15.03 & -0.03 & 0.9745 \\
\hline SOA3:related2:type3 & -39.12 & 15.07 & -2.60 & 0.0095 \\
\hline
\end{tabular}

SOA1: -100 ms; SOA2: 0 ms; SOA 3: 100 ms; type2: orthographic relatedness; type3: phonological relatedness; related2: unrelated. $p<0.0001$. For the $\mathrm{O}$ condition, the results showed that the effects of relatedness differed significantly from one another at $-100 \mathrm{~ms} \mathrm{SOA}, t(641)=7.32, p<0.0001,0 \mathrm{~ms}$ SOA, $t(633)=9.02, p<0.0001$, and $+100 \mathrm{~ms} \mathrm{SOA}, t(643)=4.95$, $p<0.0001$. For the $\mathrm{P}$ condition, the results showed that the effects of relatedness differed significantly from one another at $-100 \mathrm{~ms}$ SOA, $t(632)=4.42, p<0.0001,0 \mathrm{~ms}$ SOA, $t(632)=7.67$, $p<0.0001$ and $+100 \mathrm{~ms} \mathrm{SOA}, t(634)=6.93, p<0.0001$.

We again tested the contrasting effects via a coding of $[-1,1,-1,1,1,-1]$ across the orthographically unrelated and related, phonologically related and unrelated, and orthographically plus phonological unrelated and related cells. This analysis did not return significant results at $-100 \mathrm{~ms}$ SOA, $F(1,23)=0.900, p=0.353$, but they were significant at $0 \mathrm{~ms}$ SOA, $F(1,23)=4.611, p=0.043$ and marginally significant at $100 \mathrm{~ms} \mathrm{SOA}, F(1,23)=3.374, p=0.079$, suggesting that orthographic and phonological relatedness did not interact at an earlier stage but did interact at a later stage. Bayesian analysis as conducted in Experiment 1 resulted in a Bayes factor of 3.09 with $p \mathrm{BIC}\left(\mathrm{H}_{0} \mid \mathrm{D}\right)=0.76$ and $p \mathrm{BIC}\left(\mathrm{H}_{1} \mid \mathrm{D}\right)=0.24$ at $-100 \mathrm{~ms}$ SOA, which constitutes "positive" evidence for the null hypothesis of additive orthographic and phonological effects according to Raftery (1999). By contrast, the Bayes factor was 0.55 with $p \mathrm{BIC}\left(\mathrm{H}_{0} \mid \mathrm{D}\right)=0.35$ and $p \mathrm{BIC}\left(\mathrm{H}_{1} \mid \mathrm{D}\right)=0.65$ at $0 \mathrm{~ms}$ SOA, and 0.95 with $p \mathrm{BIC}\left(\mathrm{H}_{0} \mid \mathrm{D}\right)=0.49$ and $p \mathrm{BIC}\left(\mathrm{H}_{1} \mid \mathrm{D}\right)=0.51$ at $+100 \mathrm{~ms}$ SOA, which constitutes "weak" evidence for the interaction between orthographic and phonological relatedness in spoken production (Raftery, 1999).

A parallel analysis of variance was conducted on the errors, but binomial data were used. The best-fitting model included Relatedness and the interaction between Relatedness and Distractor Type. Adding SOA, Distractor Type, the interaction between SOA and Distractor Type, the interaction between SOA and Relatedness, and the three-way interaction among three variables did not improve the fit, $\chi^{2} \leq 3.07, p \geq 0.31$. A planned comparison showed a significant difference in the error rate in the $\mathrm{P}$ condition, $-100 \mathrm{~ms}, z=1.81, p=0.07 ; 0 \mathrm{~ms}, z=2.23$, $p=0.03 ; 100 \mathrm{~ms}, z=0.69, p=0.49$. Other comparisons were not significant, $z s \leq 1.55, p \geq 0.12$.

\section{Combination Analysis of Written and Spoken Production}

A total of 22 individuals participated in both Experiments 1 and 3 ; thus, we performed a combination analysis for onset latencies in writing and speaking. A factor of output modality (written and spoken production) was added to the previous model (SOA, Distractor Type, and Relatedness). The best-fitting model included SOA; Relatedness; Modality; the interaction between SOA and modality; the interaction between relatedness and modality; and the three-way interaction among Distractor Type, Relatedness, and Modality. The model fit did not significantly improve by adding Distractor Type, $\chi^{2}(2,10487)=2.61$, $p=0.27$; the interaction between SOA and Distractor Type, $\chi^{2}(4,10487)=2.93, p=0.57$; the interaction between SOA and Relatedness, $\chi^{2}(2,10487)=3.52, p=0.17$; the interaction between Relatedness and Distractor Type, $\chi^{2}(2,10487)=0.44$, $p=0.80$; the interaction between Distractor Type and Modality, 
$\chi^{2}(2,10487)=0.56, p=0.76$; the triple interaction among SOA, Distractor Type and Relatedness, $\chi^{2}(4,10487)=1.77, p=0.78$; the triple interaction among SOA, Distractor Type and Modality, $\chi^{2}(4,10487)=1.90, p=0.75$; the triple interaction among SOA, Relatedness and Modality, $\chi^{2}(2,10487)=2.87, p=0.24$; and the 4 -way interaction among four factors, $\chi^{2}(4,10487)=2.86$, $p=0.58$.

\section{Discussion}

The results showed that the OP related, $\mathrm{O}$ related and $\mathrm{P}$ related distractors reliably facilitated spoken production at $-100,0$, and $+100 \mathrm{~ms}$ SOAs. The striking findings were that the $\mathrm{P}$ effect occurred simultaneously with the O effect (see Zhao et al., 2012 for a similar finding), and the formula analysis indicates that the $\mathrm{O}$ effect and the $\mathrm{P}$ effect did not interact at $-100 \mathrm{~ms} \mathrm{SOA}$, although they did interact at 0 and $100 \mathrm{~ms}$ SOAs. Our findings are consistent with previous studies (Bi et al., 2009; Zhang and Weekes, 2009; Zhang et al., 2009). At an earlier stage of spoken production, we found a similar additive pattern of orthography and phonology in Chinese (Zhang et al., 2009), reflecting that the role of orthography is independent of phonology, and the orthographic distractor may activate its semantic representation at the conceptual level, thereby facilitating the conceptual identification of the target picture. At a later stage of spoken production, we found an interaction between orthographic and phonological effects, reflecting that the orthographic distractor may directly activate the corresponding phonological representation and facilitate the production of a vocal response.

\section{General Discussion}

In an adaptation of the PWI task, we investigated the temporal courses of orthographic and phonological activation in spoken and written production and addressed the contribution of orthography and phonology to written production. The results showed that the OP related and O related distractors reliably facilitated written and spoken production at $-100,0$, and $+100 \mathrm{~ms}$ SOAs. Critically, the P related effect was significant at a later stage of written production, and the difference between the $\mathrm{OP}$ and $\mathrm{O}$ conditions was not significant at $-100 \mathrm{~ms} \mathrm{SOA}$ in written production. By contrast, the P related effect was significant at an earlier stage and persisted in the later stage of spoken production. Based on the assumption that the manipulation of SOA in PWI studies allows insight into the picture-naming and picturewriting process as it unfolds over time (Qu et al., 2011), our findings at least suggest that phonology is not accessed earlier than orthography in written production, although it is accessed simultaneously with orthography in spoken production. We therefore suggest that the output modality influences the temporal pattern of phonological effects. Additionally, orthographic and phonological effects are additive in written production. However, the two effects are additive and then interact in spoken production. The findings provide evidence that orthography is not mediated by phonological information, in accordance with the orthographic autonomy hypothesis (Miceli et al., 1997; Rapp and Caramazza, 1997; Bonin et al., 1998b).
The present findings on written production are not consistent with the conclusions for English and Chinese within the PWI paradigm. In previous studies, Zhang and Damian (2010) for English and Qu et al. (2011) for Chinese found that phonology is accessed earlier than orthography. How can we interpret the reverse pattern found between studies? Our study differed from previous works in critical ways. First, previous studies inferred the temporal courses of orthography and phonology indirectly. Zhang and Damian (2010) used OP related and O related conditions in English, and they inferred the $\mathrm{P}$ effect by comparing the OP effect and the O effect. Qu et al. (2011) inferred the O effect by comparing the OP effect and the P effect. If we used only the OP and P conditions in the present study as did Qu et al. (2011), because of the lack of significant difference between the OP effect and the P effect at 0 and 100 ms SOAs in Experiment 1, we would come to the same conclusion: phonology is accessed earlier than orthography in written Chinese. However, importantly, when the $\mathrm{OP}, \mathrm{O}$, and $\mathrm{P}$ conditions were introduced into the written production system simultaneously, we observed patterns that were distinct from Qu et al.'s (2011) study with respect to the temporal course of orthographic information. The second difference was that we considered $-100 \mathrm{~ms}$ SOA in the present study. Compared to positive SOAs, the negative SOA (i.e., $-100 \mathrm{~ms}$ ) taps into the early processing stage of written production. At $-100 \mathrm{~ms} \mathrm{SOA}$, the magnitude of the OP effect $(50 \mathrm{~ms}$ in Experiment 1 and $34 \mathrm{~ms}$ in Experiment 2) was significantly larger than that of the P effect (11 ms in Experiments 1 and 2) but was not larger than the $\mathrm{O}$ effect (41 ms in Experiment 1 and $26 \mathrm{~ms}$ in Experiment 2); hence, the OP effect was primarily orthographic, not phonological. Qu et al. (2011) demonstrated that the observed phonological facilitation effect could not be attributed to priming by feedback from the phonological to conceptual level. Therefore, our findings provide consistent and reliable evidence that orthographic codes are accessed rapidly at an earlier stage, whereas phonological codes are accessed at a later stage in writing. According to the obligatory phonological mediation hypothesis, phonological activation should be activated before or simultaneously with orthographic activation in written production. Our findings therefore provide evidence for the orthographic autonomy hypothesis rather than the obligatory phonological mediation hypothesis.

As summarized in the introduction, the evidence with regard to whether handwriting is constrained by phonological codes was from healthy individuals (Bonin et al., 2001; Zhang and Damian, 2010) and patients (e.g., Miceli et al., 1999; Folk and Jones, 2004). Bonin et al. (2001) found an initial implication of phonological codes in written picture naming by varying the sound-to-print consistency of picture labels and the position of inconsistent units, suggesting that the build-up of orthographic activation from pictures is phonologically constrained via a route of sublexical conversion. Miceli et al. (1999) reported a patient ECA who produced inconsistent responses in the saythen-write condition but not in the write-then-say condition. The patient ECA was tested, and it was found that he had damage to the semantic system and to sublexical phoneme-grapheme conversion but not to sublexical grapheme-to-phoneme conversion. Hence, ECA generated inconsistent responses in only 
one direction in the double naming task, and this pattern contrasts with those that produce inconsistent lexical responses either in both say-then-write and write-then-say conditions or in neither condition. Those researchers therefore propose that phonological and orthographic lexical forms can be accessed autonomously but that they interact through sublexical conversion processes. By contrast, the present finding of early orthographic activation indicates that orthographic codes can be accessed without phonological mediation. A possibility for the divergence between studies was that different target languages were used in the work of Bonin et al. (2001) (French) and our study (Chinese). Orthography and phonology are related in alphabetic scripts such as English or French, whereas they are largely dissociated in non-alphabetic scripts such as Chinese. Therefore, it is perhaps not surprising to find an influence of phonology on orthographic output in the case of alphabetic languages.

However, findings on the role of phonology in written production have not been consistent for alphabetic languages (Bonin et al., 1998b, 2001, 2014; Roux and Bonin, 2011). For example, Bonin et al. (1998b) employed a masked priming task in which participants produced the written names of pictures and in which word primes were presented for a short duration before the pictures and were forward and backward masked. The researchers found an orthographic facilitation effect when primes were presented for 34 and $51 \mathrm{~ms}$, which, crucially, was not modulated by homophonic primes (pype-pipe) or non-homophonic primes (pope-pipe). This finding was used to argue against the role of phonology in writing. Furthermore, Roux and Bonin (2011) did not find a phonological facilitation effect using a picturepicture interference paradigm, and they suggested that phonological codes are less strongly involved in orthographic encoding. Recently, Bonin et al. (2014) found that the involvement of lexical and sublexical levels depends on the different types of written production tasks. These contradicting results for the same language question the role of phonology in handwritten production, even in alphabetic scripts. Further studies are needed to investigate the divergence among different script systems.

The different temporal patterns and interaction of orthographic and phonological effects in written and spoken production suggest that the output modality may influence the interplay of orthography and phonology in language production. Orthographic and phonological effects are additive in general, and both effects can occur independently in written production. By contrast, the two effects are additive at an earlier stage but interact at a later stage of spoken production (see Zhang et al., 2009 for similar findings but with a slightly different experimental design). If written production depends on spoken production, then we should find a similar temporal pattern of phonological and orthographic effects in written to spoken production: a phonological effect arises simultaneously with an orthographic effect. Therefore, this finding also indicates that written production is not dependent on spoken production and is thus consistent with the argument of the orthographic autonomy hypothesis.

In parallel to the issue of a phonological role in written production, an issue in spoken production is the role of orthography.
Recent findings further suggest that orthography plays a role only when it is relevant to a spoken word production task (Roelofs, 2006; Schiller, 2007; Bi et al., 2009; Zhang and Damian, 2010). In our study, the orthographic effect was observed regardless of the output modality. This finding may result from the visual distractors in the PWI task. Damian and Bowers (2009) found that the orthographic effect disappeared when distractors are presented auditorily in a PWI task. These findings indicate that the interplay between orthography and phonology is weak in language production (both spoken and written) in Chinese. Note that although contrast analysis revealed a significant interaction between orthographic and phonological relatedness in spoken production, the Bayes factor with $p \mathrm{BIC}\left(\mathrm{H}_{0} \mid \mathrm{D}\right)$ and $p \mathrm{BIC}\left(\mathrm{H}_{1} \mid \mathrm{D}\right)$ constitutes only "weak" evidence for the interaction between them.

What are the implications of our findings for written production? The written model proposed by Bonin et al. (2001) assumes a semantic system that is symmetrically linked to both a phonological and orthographic output lexicon. Both lexicons also directly map onto one another (link $\mathrm{C}$ in Figure 1), implying that the selection of a graphemic entry is influenced by both direct activation from the semantic system (link A in Figure 1) and indirect activation from the phonological lexicon via a lexical route (links B and C in Figure 1). Within such a framework, our finding of an early processing stage in which priming is dominated by orthographic relatedness suggests that the activation occurs quickly and directly from the semantic system to graphemic codes. A relatively late phonological effect suggests that activation could occur via the phonological pathway and then be transmitted to the graphemic lexicon indirectly. In the $P$ related condition, targets and distractors do not share any sublexical components except the phonological syllable. Syllables would map onto characters consisting of target names, and in comparison with an unrelated condition, the $\mathrm{P}$ related distractors would generate a facilitation effect. We therefore suggest that orthographic codes can be accessed via a lexical route rather than a sublexical route in the present study. We do not deny the role of phonology in written production, but phonological influence was not mandatory and universal, and it can be modulated via experimental manipulations (see Zhang and Damian, 2010 for a similar conclusion based on an articulation suppression task).

\section{Conclusion}

We found an orthographic effect at an early stage in written production, reflecting a fast and direct link between meaning and graphemic lexicon, and we demonstrated that orthographic codes can be accessed directly from meaning in healthy adults. We also found orthographic and phonological effects at a later stage, reflecting a slow and indirect link between meaning and graphemic lexicon via phonology. Furthermore, the absence of an interaction effect of orthographic and phonological facilitation on written latencies suggests that the two effects are additive in general but that they might occur independently in written production in Chinese. Concerning the process of spoken 
production, we found that orthographic and phonological effects occur simultaneously and that both effects are additive at an early stage but interactive at a later stage. The temporal courses and their interplay of orthographic and phonological effects are dissociative in written and spoken production. Our findings support the orthography autonomy hypothesis, rather than obligatory phonological mediation hypothesis, for written production.

\section{References}

Afonso, O., and Álvarez, C. J. (2011). Phonological effects in handwriting production: evidence from the implicit priming paradigm. J. Exp. Psychol. Learn. Mem. Cogn. 37, 1474-1483. doi: 10.1037/a0024515

Aitchison, J., and Todd, P. (1982). "Slips of the mind and slips of the pen," in Language and Cognitive Styles: Patterns of Neurolinguistic and Psycholinguistic Development, eds B. N. Chir and W. Von Raffler-Engel (Lisse: Swets and Zeitlinger), 180-194.

Alario, F. X., Schiller, N. O., Domoto-Reilly, K., and Caramazza, A. (2003). The role of phonological and orthographic information in lexical selection. Brain Lang. 84, 372-398. doi: 10.1016/S0093-934X(02)00556-4

Baayen, R. H., Davidson, D. J., and Bates, D. M. (2008). Mixed-effects modeling with crossed random effects for subjects and items. J. Mem. Lang. 59, 390-412. doi: 10.1016/j.jml.2007.12.005

Balota, D. A., and Paul, S. T. (1996). Summation of activation: evidence from multiple primes that converge and diverge within semantic memory. J. Exp. Psychol. Learn. Mem. Cogn. 22, 827-845. doi: 10.1037/0278-7393.22.4.827

Basso, A., Taborelli, A., and Vignolo, L. A. (1978). Dissociated disorders of speaking and writing in aphasia. J. Neurol. Neurosurg. Psychiatry 41, 556-563. doi: 10.1136/jnnp.41.6.556

Bates, D. (2005). Fitting Linear Mixed Models in R. R News, 5(1), Article 5. Available at: http://ftp.cs.pu.edu.tw/network/CRAN/doc/Rnews/Rnews_2005-1.pdf

Baus, C., Strijkers, K., and Costa, A. (2013). When does word frequency influence written production? Front. Psychol. 4:963. doi: 10.3389/fpsyg.2013. 00963

Beijing Language Institute. (1986). In: Modern Chinese Frequency Dictionary in Chinese). Beijing: Beijing Language Institute Publisher.

Bi, Y., Wei, T., Janssen, N., and Han, Z. (2009). The contribution of orthography to spoken word production: evidence from mandarin Chinese. Psychon. Bull. Rev. 16, 555-560. doi: 10.3758/pbr.16.3.555

Bonin, P., and Fayol, M. (2000). Writing words from pictures: what representations are activated, and when? Mem. Cogn. 28, 677-689. doi: 10.3758/BF032 01257

Bonin, P., Fayol, M., and Gombert, J.-E. (1997). Role of phonological and orthographic codes in picture naming and writing: an interference paradigm study. Curr. Psychol. Cogn. 16, 299-324.

Bonin, P., Fayol, M., and Gombert, J.-E. (1998a). An experimental study of lexical access in the writing and naming of isolated words. Int. J. Psychol. 33, 269-286. doi: 10.1080/002075998400312

Bonin, P., Fayol, M., and Peereman, R. (1998b). Masked form priming in writing words from pictures: evidence for direct retrieval of orthographic codes. Acta Psychol. 99, 311-328. doi: 10.1016/S0001-6918(98)00017-1

Bonin, P., Méot, A., Lagarrigue, A., and Roux S. (2014). Written object naming, spelling to dictation and immediate copying: different tasks, different pathways? Q. J. Exp. Psychol. doi: 10.1080/17470218.2014.978877 [Epub ahead of print].

Bonin, P., Méot, A., Millotte, S., and Barry, C. (2013). Individual differences in adult handwritten spelling-to-dictation. Front. Psychol. 4:402. doi: 10.3389/fpsyg.2013.00402

Bonin, P., Peereman, R., and Fayol, M. (2001). Do phonological codes constrain the selection of orthographic codes in written picture naming? J. Mem. Lang. 45, 688-720. doi: 10.1006/jmla.2000.2786

Caramazza, A. (1997). How many levels of processing are there in lexical access? Cogn. Neuropsychol. 14, 177-208. doi: 10.1080/026432997381664

Caramazza, A., Berndt, R. S., and Basili, A. G. (1983). The selective impairment of phonological processing: a case study. Brain Lang. 18, 128-174. doi: 10.1016/0093-934X(83)90011-1

\section{Acknowledgments}

This research was supported by grants from the National Natural Science Foundation of China (31170977, 31471074), the Fundamental Research Funds for the Central Universities, and the Research Funds of Renmin University of China (No. 14NXLF12) to QZ.

Caramazza, A., and Hillis, A. E. (1990). Where do semantic errors come from? Cortex 26, 95-122. doi: 10.1016/S0010-9452(13)80077-9

Damian, M. F., and Bowers, J. S. (2009). Assessing the role of orthography in speech perception and production: evidence from picture-word interference tasks. Eur. J. Cogn. Psychol. 21, 581-598. doi: 10.1080/095414408018 96007

Damian, M. F., Dorjee, D., and Stadthagen-Gonzalez, H. (2011). Long-term repetition priming in spoken and written word production: evidence for a contribution of phonology to handwriting. J. Exp. Psychol. Learn. Mem. Cogn. 37, 813-826. doi: 10.1037/a0023260

Damian, M. F., and Martin, R. C. (1999). Semantic and phonological codes interact in single word production. J. Exp. Psychol. Learn. Mem. Cogn. 25, 345-361. doi: 10.1037/0278-7393.25.2.345

Damian, M., and Qu, Q. (2013). Is handwriting constrained by phonology? Evidence from Stroop tasks with written responses and Chinese characters. Front. Psychol. 4:765. doi: 10.3389/fpsyg.2013.00765

Dell, G. S. (1986). A spreading-activation theory of retrieval in sentence production. Psychol. Rev. 93, 283-321. doi: 10.1037/0033-295x.93.3.283

Dell, G. S. (1988). The retrieval of phonological forms in production: tests of predictions from a connectionist model. J. Mem. Lang. 27, 124-142. doi: 10.1016/0749-596X(88)90070-8

Ellis, A. W. (1982). "Spelling and writing (and reading and speaking)," in Normality and Pathology in Cognitive Functions, ed. A. W. Ellis (New York, NY: Academic Press).

Ellis, A. W. (1988). Normal writing processes and peripheral acquired dysgraphias. Lang. Cogn. Process. 3, 99-127. doi: 10.1080/01690968808402084

Folk, J. R., and Jones, A. C. (2004). The purpose of lexical/sublexical interaction during spelling: further evidence from dysgraphia and articulatory suppression. Neurocase 10, 65-69. doi: 10.1080/13554790490960512

Geschwind, N. (1969). "Problems in the anatomical understanding of the aphasias," in Contributions to Clinical Neuropsychology, ed. A. L. Benton (Chicago: Aldine).

Hanley, J. R., and McDonnell, V. (1997). Are reading and spelling phonologically mediated? Evidence from a patient with a speech production impairment. Cogn. Neuropsychol. 14, 3-33. doi: 10.1080/026432997381600

Hotopf, W. H. N. (1980). "Slips of the pen," in Cognitive Processes in Spelling, ed. U. Frith (New York: Academic Press), 287-307.

Levelt, W. J. M., Roelofs, A., and Meyer, A. S. (1999). A theory of lexical access in speech production. Behav. Brain Sci. 22, 1-38. doi: $10.1017 /$ S0140525X99001776

Luria, A. R. (1970). Traumatic Aphasia. Mouton: The Hague. doi: $10.1515 / 9783110816297$

Masson, M. J. (2011). A tutorial on a practical Bayesian alternative to null-hypothesis significance testing. Behav. Res. Methods 43, 679-690. doi: 10.3758/s13428-010-0049-5

Melinger, A., and Abdel Rahman, R. (2004). Investigating the interplay between semantic and phonological distractor effects in picture naming. Brain Lang. 90, 213-220. doi: 10.1016/S0093-934X(03)00434-6

Miceli, G., Benvegnù, B., Capasso, R., and Caramazza, A. (1997). The independence of phonological and orthographic lexical forms: evidence from aphasia. Cogn. Neuropsychol. 14, 35-69. doi: 10.1080/026432997381619

Miceli, G., Capasso, R., and Caramazza, A. (1999). Sublexical conversion procedures and the interaction of phonological and orthographic lexical forms. Cogn. Neuropsychol. 16, 557-572. doi: 10.1080/026432999380726

Qu, Q., Damian, M. F., Zhang, Q., and Zhu, X. (2011). Phonology contributes to writing: evidence from written word production in a nonalphabetic script. Psychol. Sci. 22, 1107-1112. doi: 10.1177/0956797611417001 
Raftery, A. E. (1999). Bayes factors and BIC: comment on "A critique of the Bayesian information criterion for model selection." Sociol. Methods Res. 27, 411-427. doi: 10.1177/0049124199027003005

Rapp, B., Benzing, L., and Caramazza, A. (1997). The autonomy of lexical orthography. Cogn. Neuropsychol. 14, 71-104. doi: 10.1080/026432997381628

Rapp, B., and Caramazza, A. (1997). From graphemes to abstract letter shapes: levels of representation in written spelling. J. Exp. Psychol. Hum. Percept. Perform. 23, 1130-1152. doi: 10.1037/0096-1523.23.4.1130

R Development Core Team. (2009). $R$ : A Language and Environment for Statistical Computing. (version 2.8.1). [Software]. Vienna: R Foundation for Statistical Computing.

Roelofs, A. (2001). Set size and repetition matter: comment on Caramazza and Costa (2000). Cognition 80, 283-290. doi: 10.1016/S0010-0277(01)00134-2

Roelofs, A. (2006). The influence of spelling on phonological encoding in word reading, object naming, and word generation. Psychon. Bull. Rev. 13, 33-37. doi: 10.3758/bf03193809

Roux, S., and Bonin, P. (2011). Cascaded processing in written naming: evidence from the picture-picture interference paradigm. Lang. Cogn. Process. 27, 734-769. doi: 10.1080/01690965.2011.580162

Schiller, N. (2007). Phonology and orthography in reading aloud. Psychon. Bull. Rev. 14, 460-465. doi: 10.3758/BF03194089

Schriefers, H., Meyer, A. S., and Levelt, W. J. M. (1990). Exploring the time course of lexical access in language production: picture-word interference studies. J. Mem. Lang. 29, 86-102. doi: 10.1016/0749-596X(90) 90011-N

Starreveld, P. A., and La Heij, W. (1995). Semantic interference, orthographic facilitation, and their interaction in naming tasks. J. Exp. Psychol. Learn. Mem. Cogn. 21, 686-698. doi: 10.1037/0278-7393.21.3.686

Starreveld, P. A., and La Heij, W. (1996a). The locus of orthographic-phonological facilitation: reply to Roelofs, Meyer, and Levelt (1996). J. Exp. Psychol. Learn. Mem. Cogn. 22, 252-255. doi: 10.1037/0278-7393.22.1.252
Starreveld, P. A., and La Heij, W. (1996b). Time-course analysis of semantic and orthographic context effects in picture naming. J. Exp. Psychol. Learn. Mem. Cogn. 22, 896-918. doi: 10.1037/0278-7393.22.4.896

Zhang, Q., Chen, H.-C., Weekes, B. S., and Yang, Y. (2009). Independent effects of orthographic and phonological facilitation on spoken word production in Mandarin. Lang. Speech 52, 113-126. doi: 10.1177/0023830908099885

Zhang, Q., and Damian, M. (2010). Impact of phonology on the generation of handwritten responses: evidence from picture-word interference tasks. Mem. Cogn. 38, 519-528. doi: $10.3758 / \mathrm{mc} .38 .4 .519$

Zhang, Q., and Wang, C. (2014). Syllable frequency and word frequency effects in spoken and written word production in a non-alphabetic script. Front. Psychol. 5:120. doi: 10.3389/fpsyg.2013.00120

Zhang, Q., and Weekes, B. S. (2009). Orthographic facilitation effects on spoken word production: evidence from Chinese. Lang. Cogn. Process. 24, 1082-1096. doi: 10.1080/01690960802042133

Zhang, Q., and Yang, Y. (2003). The determiners of picture-naming latency (in Chinese). Acta Psychol. Sinica 35, 447-454.

Zhao, H., La Heij, W., and Schiller, N. O. (2012). Orthographic and phonological facilitation in speech production: new evidence from picture naming in Chinese. Acta Psychol. (Amst.) 139, 272-280. doi: 10.1016/j.actpsy.2011.12.001

Conflict of Interest Statement: The authors declare that the research was conducted in the absence of any commercial or financial relationships that could be construed as a potential conflict of interest.

Copyright $\odot 2015$ Zhang and Wang. This is an open-access article distributed under the terms of the Creative Commons Attribution License (CC BY). The use, distribution or reproduction in other forums is permitted, provided the original author(s) or licensor are credited and that the original publication in this journal is cited, in accordance with accepted academic practice. No use, distribution or reproduction is permitted which does not comply with these terms. 